\title{
RESISTÊNCIA DE SOJA A INSETOS: IX. AMOSTRAGEM PARA AVALIAÇÃO DE DANO DE PERCEVEJO (')
}

\author{
VIOLETA NAGAI $(2,4)$, CARLOS JORGE ROSSETTO $(3,4)$ \\ Q ANDRÉ LUIZ LOURENÇÃO $(3,4)$
}

\begin{abstract}
RESUMO
As avaliaçōes de dano, na seleção de cultivares de soja resistentes ao percevejo, realizadas no Instituto Agronômico de Campinas, têm sido feitas pela produção de grãos, porcentagem de retenção foliar (PRF) e indice porcentual de dano de vagens (IPDV). Na aplicação do IPDV, têm sido utilizadas amostras da regiāo mediana das plantas. Neste trabalho, procurou-se verificar o número de blocos, de plantas e de vagens por planta necessários para detectar, estatisticamente, diferenças de $10 \%$ entre médias de danos em dois genótipos de soja, um resistente e ou. : suscetível a percevejos. Para que diferenças dessa magnitude sejam significativas ao nfvel de $5 \%$, deve-se utilizar um minimo de quatro blocos, oito plantas por bloco e cinco vagens por planta.
\end{abstract}

Termos de indexação: soja, Glycine max (L.) Merrill, melhoramento genético, índice de dano, tamanhe ds amostra; percevejos, Pentatomidae, resisténcia.

(1) Recebido para publicação em 2 de fevereiro de 1987.

(2) Seção de Técnica Experimental e Cálculo, Instituto Agronômico (IAC), Caixa Postal 28, 13001 Campinas (SP).

(3) Seção de Entomologia Fitotécnica, IAC.

(4) Com bolsa de pesquisa do CNPq. 


\section{INTRODUÇÃO}

Em pesquisas de resistência a insetos, a avaliação de danos é, em geral, feita em amostras da população. A quantidade de informação nelas contida depende do método de obtenção dos dados e do número de unidades incluídas. O controle do número de unidades e o emprego de pessoal treinado para fazer as avaliaçōes minimizam as diferenças entre os parâmetros estimados e os populacionais.

$\mathrm{Na}$ seleção de cultivares menos suscetiveis, a determinação do tamanho da amostra é feita em função da diferença entre médias que se considera importante e deseja detectar. NAGAl (1984) determinou o tamanho mínimo de amostra para detecção, por teste estatístico, de diferenças de $10 \%$ da média geral entre médias de tratamento, em estudos de avaliação de danos causados pela lagarta da espiga e pelo caruncho, em milho.

A Seção de Entomologia Fitotécrica, em colaboração com a de Leguminosas (Instituto Agronômico), vem desenvolvencio, desde 1976, um programa de pesquisa com a finalidade de obter cultivares de soja resistentes aos percevejos da família Pentatomidae (LOURENÇĀO et al., 1985).

Os danos são avaliados pela produção, porcentagem de retenção foliar (PRF) e indice porcentual de dano de vagens (IPDV) (ROSSETTO et al., 1986). A produção é estimada, pesando-se os grăos comerciáveis; a PRF é uma estimativa visuai no momento da colheita e o IPDV, uma modificação, sugerida por ROSSETTO et al. (1986), do índice IDV proposto, em 1984, por esses autores, para estimar o dano causado pelos percevejos às vagens de soja. Segundo ROSSETTO et al. (1984), há necessidade de comparar a eficiência do índice de dano na vagem com uma leitura direta do dano, que seria fornecida pela porcentagem de lojas vazias (PLV). É objetivo do presente trabaiho comparar os métodos IPDV e PLV e a determinação do tamanho da amostra que permita detectar diferenças de $10 \%$ entre médias de danos causados por percevejos em genótipos de soja, quando empregados esses métodos de avaliaçāo de danos.

\section{MATERIAL E MÉTODOS}

O cultivar de soja Paraná, suscetivel ao percevejo, a a linhagem IAC 80/596-2, resistente, foram estudados em um delineamento em blocos ao acaso com dez repetições, plantado em 17-12-1982, no Centro Experimental de Campinas (Instituto Agronômico). Nas fases de enchimento de vagens, efetuaram-se infestações artificiais com adultos de Piezodorus guildinii (West.), Nezara viridula (L.) e Euschistus heros (Fabr.), totalizando dois mil insetos. Cada parcela foi constituída de uma linha de $6 \mathrm{~m}$, em cuja colheita realizaram-se três diferentes formas de amostragem: (a) 5 plantas e 20 vagens por planta; (b) 10 plantas e 10 vagens por planta; e (c) 20 plantas e 5 vagens por planta. 
As vagens foram classificadas em cheias, quando todas as lojas revelavam aspecto normal de grãos desenvolvidos; em chatas ou vazias, quando todas as lojas se apresentavam sem grãos desenvolvidos, e em intermediárias, quando pelo menos uma loja estava achatada e uma cheia.

Em cada planta, avaliaram-se os danos pela porcentagem de lojas vazias (PLV) e pelo índice percentual de dano de vagens (IPDV), calculado pela fórmula seguinte:

$$
I P D V=1 / 2(\% \text { vagens intermediárias })+(\% \text { vagens chatas })
$$

As análises de variância foram feitas de acordo com o modelo matemático:

$$
Y_{i j k}=m+t_{i}+b_{j}+(t b)_{i j}+e_{i j k}
$$

onde:

$$
\begin{aligned}
& i=1,2, \ldots l \\
& j=1,2, \ldots J \\
& k=1,2, \ldots K
\end{aligned}
$$

No modelo, $e_{i j k}$ com distribuição $N\left(0, \sigma_{e}^{2}\right)$ é o único efeito aleatório e corresponde a plantas dentro de tratamentos, dentro de blocos.

A estimativa de variância de média $\hat{V}(\bar{Y})$, é obtida a partir da expressão: $\hat{V}(\bar{Y})=\hat{\sigma}_{\mathrm{e}}^{2} / \mathrm{JK}$.

Para determinação do tamanho da amostra, considerou-se que diferenças ( $\hat{d})$ de $10 \%$ no mínimo entre médias de danos em genótipos $-\left(\hat{d}=m_{i}-m_{i}^{\prime}\right)-$ deveriam ser detectadas na análise estatística.

Pela restrição:

$$
\operatorname{Pr} \frac{\left(i m_{i}-m_{i}^{\prime} \mid<10 \%\right)=1-\alpha}{\operatorname{Pr}\left(\frac{\left|m_{i}-m_{i}^{\prime}\right|}{s(\bar{d})}<\frac{d}{s(\bar{d})}\right)=1-\alpha}
$$

onde $s(\tilde{d})=\sqrt{\frac{2 \sigma_{\mathrm{e}}^{2}}{\mathrm{JK}}}$

$$
\operatorname{Pr}\left(\mathrm{t}<\mathrm{t}_{0}\right)=1-\alpha
$$

Assim, JK $=\frac{2 \mathrm{t}_{\mathrm{\rho}}^{2} \bar{\sigma}_{\mathrm{e}}^{2}}{\mathrm{~d}^{2}}$ 
O valor de $t_{0}$, obtido com o número de graus de liberdade correspondente à soma de quadrados de plantas dentro de tratamentos, dentro de blocos, foi aproximado para $\mathrm{t}_{0}=2, \operatorname{com} \alpha=0,05$.

A partir da estimativa de $\sigma_{\mathrm{e}^{\prime}}^{2}$ delinearam-se diferentes esquemas de amostragem, de modo a satisfazer ao critério estabelecido.

\section{RESULTADOS E DISCUSSÃO}

No quadro 1, observa-se que a variabilidade $\left(\sigma_{\mathrm{e}}^{2}\right)$ aumentou ao se tomar maior número de plantas e menor número de vagens, por planta, enquanto a estimativa da variância da média, $\hat{V}(\bar{\gamma})$, diminuiu.

Observa-se, ainda, que nas duas variedades e nos três tipos de amostragem, os dois métodos, PLV e IPDV, são altamente correlacionados e podem ser utilizados com eficiência semelhante. Essa alta correlação era esperada visto que ambas procuram medir a porcentagem de lojas danificadas pelos percevejos. O PLV é uma medida direta desse dano, enquanto o IPDV procura estimá-lo através de um método mais rápido de classificação das vagens, sem necessidade de contar as lojas individualmente. Como o IPDV demonstrou ser uma estimativa bem aproximada do PLV e como sua obtençāo é menos trabalhosa, recomenda-se o seu uso para avaliar danos de percevejos da soja.

QUADRO 1. Estimativas de parâmetros, relativos ảs análises de três tipos de amostragem, utilizados na avaliação de danos por percevejos em vagens dos cultivares de soja $\mathrm{Pa}$ raná e IAC 80/596-2, em campo. Campinas, 1982

\begin{tabular}{|c|c|c|c|c|c|c|c|c|c|}
\hline \multirow{2}{*}{$\begin{array}{l}\text { Tipo de } \\
\text { amostragem }\end{array}$} & \multirow{2}{*}{$\begin{array}{c}\text { Método } \\
\text { de avaliação } \\
\text { de dano (1) }\end{array}$} & \multicolumn{8}{|c|}{ Estimativas (2) } \\
\hline & & $\bar{y}_{1}$ & $\bar{y}_{2}$ & $\bar{Y}$ & $\hat{V}(\bar{Y})$ & $\sigma_{\mathrm{e}}^{2}$ & $\mathrm{~F}$ & $r_{1}$ & $r_{2}$ \\
\hline \multirow{2}{*}{$\begin{array}{l}20 \text { vagens } \\
\text { por planta } \\
\text { em } 5 \text { plantas }\end{array}$} & PLV & 43,38 & 13,13 & 28,26 & 2,34 & 234,10 & 97,73 & \multirow{2}{*}{0,97} & \multirow{2}{*}{0,98} \\
\hline & IPDV & 44,11 & 13,11 & 28,61 & 2,07 & 206,92 & 116,08 & & \\
\hline \multirow{2}{*}{$\begin{array}{l}10 \text { vagens } \\
\text { por planta } \\
\text { em } 10 \text { plantas }\end{array}$} & PLV & 41,77 & 8,76 & 25,26 & 1,43 & 286,89 & 189,98 & \multirow{2}{*}{0,98} & \multirow{2}{*}{0,98} \\
\hline & IPDV & 43,06 & 8,61 & 25,83 & 1,35 & 271,95 & 217,50 & & \\
\hline \multirow{2}{*}{$\begin{array}{l}5 \text { vagens } \\
\text { por planta } \\
\text { em } 20 \text { plantas }\end{array}$} & PLV & 41,77 & 10,26 & 25,71 & 0,98 & 391,01 & 243,44 & \multirow{2}{*}{0,98} & \multirow{2}{*}{0,96} \\
\hline & IPDV & 41,98 & 10,70 & 26,34 & 0,96 & 383,65 & 250,40 & & \\
\hline
\end{tabular}

(1) PLV = porcentagem de lojas vazias; IPDV = Indice porcentual de dano por vagem. (2) $\overline{y_{1}}=$ média do cultivar Paraná; $\bar{y}_{2}=$ média do cultivar IAC $80 / 596-2, \bar{Y}=$ média do experimento global; $\hat{V}(\bar{Y})=$ estimativa da variância da média; $\hat{\sigma}_{\mathrm{e}}^{2}=$ estimativa da variância entre plantas dentro de tratamentos e dentro de blocos; $\mathrm{F}=$ valores da prova de $F$ para tratamentos; $r_{1} \in r_{2}=$ coeficientes de correlação entre a porcentagem de lojas vazias e o índice porcentual de dano de vagem para os cultivares Paranå e IAC 80/596-2 respectivamente. 
Vê-se, pelo quadro 2, que os resultados obtidos pelos dois índices de dano foram semelhantes em termos de tamanho de amostra. Nele são indicadas, para diferentes números de repetições, a partir de quatro (que, de modo geral, é o mínimo utilizado em ensaios de campo), quantas plantas devem ser usadas na avaliação de danos causados por percevejos da soja, com o objetivo de discriminar genótipos com diferentes graus de dano. Ao se tomarem 20 vagens por planta, o núinero total de vagens a avaliar por bloco é maior que o dobro daquele da amostra constituida de cinco vagens por planta. $\dot{E}$, portanto, mais vantajoso utilizar maior número de plantas com menor número de vagens retiradas de cada planta. Isso facilita, ainda, a tomada da amostra, pois, na seleção de vinte vagens, a planta amostrada pode não conter esse número de vagens. Os resultados obtidos comprovam que o tamanho de amostra que vem sendo empregado pela Seção de Entomologia para avaliação de danos causados pelo percevejo da soja - 100 vagens distribuidas em vinte ou mais plantas por parcela - satisfaz plenamente à precisão requerida nos ensaios.

QUADRO 2. Número de repetições e número de plantas por parcela a serem utilizados em avaliações de danos causados pelo percevejo da soja, pelos métodos porcentagem de lojas vazias (PLV) e indice percentual de danos de vagens (IPDV) quando tomadas amostras de 5,10 ou 20 vagens por planta

\begin{tabular}{|c|c|c|c|c|c|c|c|c|}
\hline \multirow{2}{*}{$\begin{array}{l}\text { Número de vagens } \\
\text { por planta }\end{array}$} & \multirow{2}{*}{$\begin{array}{l}\text { Método de } \\
\text { avaliaçāo }\end{array}$} & \multicolumn{7}{|c|}{ Repetiçōes } \\
\hline & & 4 & 5 & 6 & 7 & 8 & 9 & 10 \\
\hline & & \multicolumn{7}{|c|}{ Plantas/parcela } \\
\hline 5 & $\begin{array}{l}\text { PLV } \\
\text { IPDV }\end{array}$ & $\begin{array}{l}8 \\
8\end{array}$ & $\begin{array}{l}7 \\
7\end{array}$ & $\begin{array}{l}6 \\
6\end{array}$ & $\begin{array}{l}5 \\
5\end{array}$ & $\begin{array}{l}4 \\
4\end{array}$ & $\begin{array}{l}4 \\
4\end{array}$ & $\begin{array}{l}3 \\
3\end{array}$ \\
\hline 10 & $\begin{array}{l}\text { PLV } \\
\text { IPDV }\end{array}$ & $\begin{array}{l}6 \\
6\end{array}$ & $\begin{array}{l}5 \\
5\end{array}$ & $\begin{array}{l}4 \\
4\end{array}$ & $\begin{array}{l}4 \\
4\end{array}$ & $\begin{array}{l}3 \\
3\end{array}$ & $\begin{array}{l}3 \\
3\end{array}$ & $\begin{array}{l}3 \\
3\end{array}$ \\
\hline 20 & $\begin{array}{l}\text { PLV } \\
\text { IPDV }\end{array}$ & $\begin{array}{l}5 \\
5\end{array}$ & $\begin{array}{l}4 \\
4\end{array}$ & $\begin{array}{l}4 \\
3\end{array}$ & $\begin{array}{l}3 \\
3\end{array}$ & $\begin{array}{l}3 \\
3\end{array}$ & $\begin{array}{l}2 \\
2\end{array}$ & $\begin{array}{l}2 \\
2\end{array}$ \\
\hline
\end{tabular}

\section{CONCLUSÕES}

1. Os métodos porcentagem de lojas vazias (PLV) e índice percentual de danos de vagens (IPDV) podem ser utilizados com a mesma eficiência na avaliaçāo de danos causados por percevejos em soja. Dada a maior facilidade e rapidez de aplicação, o índice IPDV pode substituir o PLV. 
2. É preferivel empregar maior númerc de plantas e menor número de vagens por planta para avaliação de danos por ambos os métodos.

3. Amostras de cinco vagens por planta em seis plantas de cada um de seis blocos ou em sete plantas de cinco blocos, ou, ainda, em oito plantas em quatro blocos, permitem detectar diferenças de $10 \%$ entre médias de tratamentos, com diferentes graus de dano de percevejos de soja, estimados pelos índices PLV e IPDV.

\section{SUMMARY \\ RESISTANCE OF SOYBEAN TO INSECTS. IX. SAMPLING FOR EVALUATION OF STINK BUG DAMAGE}

Two ways of estimating the damage done by stink bugs to the soybean pods were compared: the direct counting of flat loculi (FL), which gives a percentage of damage and an index called Percentual Index of Pod Damage (PIPD). The PIPD is obtained by classifying the pods in three categories (flat, intermediate and sound) and applying the formula PIPD $=1 / 2$ (percentage of intermediate pods) + percentage of flat pods. The FL and PIPD are highly correlated $(r \geqslant 0.96)$. The use of the PIPD is recommended since it is easier to obtain. Three ways of sampling were compared: a) Twenty pods from five plants; b) Ten pods from ten plants; c) Five pods from twenty plants. It was demonstrated that it is more advantageous to use less pods per plant and more plants per plot.

Index terms: soybean, Glycine max (L.) Merrill, stink bugs, Pentatomidae, pod damage index, sampling, insect resistance, soybean breeding.

\section{REFERÊNCIAS BIBLIOGRÁFICAS}

LOURENÇĀO, A.L.; ROSSETTO, C.J. \& MIRANDA, M.A.C. de. Resistência de soja a insetos. III. Seleção de linhagens resistentes a percevejos. Bragantia, Campinas, 44(1):77-86, 1985.

NAGAI, V. Técnica de amostragem para comparar o dano causado por Heliothis zea (Boddie) e Sitophilus zeamais Motschuisky, em cultivares de milho. Piracicaba, Escola Superior de Agricultura “Luiz de Queiroz", 1984. 97p. Tese (Mestr.) Estatística. Dep. Matem. e Estat. da ESALQ/USP.

ROSSETTO, C.J.; IGUE, T.; MIRANDA, M.A.C. de \& LOURENÇĀO, A.L. Resistência de soja a insetos. VI. Comportamento de genótipos em relaçāo a percevejos. Bragantia, Campinas, 45(2):323-335, 1986.

; LOURENÇÃO, A.L.; MIRANDA, M.A.C. de \& IGUE, T. Resistência de soja a insetos. II. Teste de livre escolha entre a linhagem IAC 73/228 e o cultivar Paraná, infestados por Nezara viridula (L.) em telado. Bragantia, Campinas 43(1):141-153, 1984. 